\title{
Effects of temperature and resource abundance on small- and large-bodied cladocerans: Community stability and species replacement
}

\author{
Irina Yu. Feniova ${ }^{1}$, Anna L. Palash ${ }^{2}$, Vladimir I. Razlutskij ${ }^{2}$, Andrew R. Dzialowski ${ }^{3}$ \\ ${ }^{1}$ A. N. Severtsov Institute of Ecology and Evolution, Russian Academy of Sciences, Moscow, Russia;
${ }^{*}$ Corresponding Author: feniova@mail.ru
${ }^{2}$ The Scientific and Practical Center for Bioresources, National Academy of Sciences of Belarus, Minsk, Republic of Belarus
${ }^{3}$ Department of Zoology, Oklahoma State University, Stillwater, USA
}

Received 20 January 2013; revised 19 February 2013; accepted 17 March 2013

Copyright (C) 2013 Irina Yu. Feniova et al. This is an open access article distributed under the Creative Commons Attribution License, which permits unrestricted use, distribution, and reproduction in any medium, provided the original work is properly cited.

\begin{abstract}
Understanding when small- or large-bodied cladocerans dominate zooplankton communities has received considerable debate over the past 50 years. While a large body of research has proposed that large-bodied species are superior competitors over small-bodied species, other studies have shown that small-bodied species can dominate at least under some environmental conditions. We tested the hypothesis that dominance by small- and large-bodied cladocerans varied in response to the coupled effects of food supply and temperature. Laboratory experiments with poly- and monocultures of small- and large-bodied cladocerans were performed at three temperatures $\left(16^{\circ} \mathrm{C}, 22^{\circ} \mathrm{C}\right.$ and $27^{\circ} \mathrm{C}$ ) and with varying amounts of food supply. The results of the experiments showed that the small-bodied species (Ceriodaphnia quadrangula) dominated at low food supply and higher temperature, while the large-bodied species (Daphnia magna and Daphnia pulex) in contrast dominated at lower temperature and higher food supply. Furthermore, although there were variations in the relative biomass of the small- and large-bodied cladocerans in the polycultures, $C$. quandrangula replaced the two larger Daphnia species when they declined in biomass at low food supply. Species replacement in response to temperature and food supply helped to maintain the relatively constant level of total cladoceran biomass in the polycultures which was the most pronounced at the intermediate temperature. We suggest that the observed changes in domi-
\end{abstract}

nance were similar to facilitative replacement rather than competitive exclusion. Physiological processes such as clearance rates can help to promote the succession of large- and smallbodied populations within a community along gradients of temperature and food availability.

Keywords: Cladocera; Laboratory Experiments; Biomass; Food Supply Effects; Temperature Effects; Food Limitation

\section{INTRODUCTION}

A large body of research has focused on understanding the interactions between large- and small-bodied cladocerans. Brooks and Dodson [1] proposed that in the absence of fish predation, large-bodied species were competitively superior to small-bodied species (i.e., the Size Efficiency Hypothesis; [1]). While many studies have supported the predictions of the Size Efficiency Hypothesis [2,3], there is also a large body of research showing that small-bodied cladocerans are superior competitors [4-7]. Based on these contradictory results, therefore, it is possible that dominance by either large- or small-bodied cladocerans is dependent on environmental conditions. For example, large-bodied cladocerans may dominate under one set of environmental conditions, but be replaced by small-bodied cladocerans under a different set of environmental conditions.

Temperature and resource availability are two environmental factors that not only regulate cladoceran abundance and community structure in general [8-12], but also likely influence interactions between large- and small-bodied taxa. With respect to temperature, Moore et al. [13] hypothesized that the competitive ability of 
small-bodied cladocerans increases with increasing temperature. One reason for this increase may be that the energy requirements of small-bodied taxa increase at a slower rate with increasing temperature compared to large-bodied taxa [13]. In support, several field studies have shown that small-bodied cladocerans dominate in warmer subtropical and tropical fresh waters, a finding which has been contributed at least in part to higher temperatures [14,15]. Combined, these studies suggest that small-bodied cladoceran species may be able to replace large-bodied cladocerans at higher temperatures.

The effects of temperature on cladocerans, however, are influenced by food availability and strong interactive effects of temperature and food concentration on the development, reproduction and population growth of cladocerans have been well documented $[13,16]$. Both temperature and food availability affect metabolic processes and as a result their combined impacts on individuals are linked to life history responses $[17,18]$. Furthermore, processes at the individual and population level are linked because metabolism sets both the demand for environmental resources and the resource allocation to survival, growth and reproduction [17]. For example, Orcutt and Porter [19] and Foran [5] found that the effects of temperature on Daphnia's $r$ (population rate of increase) were reduced when algal resources were low. Giebelhausen and Lampert [16] also suggested that the fitness of D. magna was influenced by both temperature and food availability, while Gama-Flores et al. [20] experimentally showed that small Ceriodaphnia dubia and Daphnia pulex had different responses to the combined effects of food concentration and temperature. While these studies provided evidence that the effects of temperature on cladocerans are dependent on food availability, additional research is needed to better understand the coupled effects of temperature and food availability on cladoceran body size.

There are physiological constraints to the acceleration of development with temperature [13,16]. High metabolic losses at elevated temperature can be compensated only if there is sufficient energy uptake. Thus cladoceran filtration rate should be enhanced as temperature increases and research has shown that filtration rate generally increases with both temperature and body size. However, cladocerans differ in their filtering responses to high temperatures and each species reaches a temperature maximum where filtering rate begins to decrease [21]. Furthermore, filtration rate is influenced by algal food concentration and filtration rates can decline at high food levels. Therefore, how the filtration rates of different cladocerans vary in response to the coupled effects of temperature and food availability should help to understand whether small- or large-bodied cladocerans are able to dominate communities.
We designed a series of laboratory experiments with poly- and monocultures of small- and large-bodied cladocerans at three temperatures $\left(15^{\circ} \mathrm{C}, 21^{\circ} \mathrm{C}\right.$ and $\left.27^{\circ} \mathrm{C}\right)$ and with varying amounts of food supply to determine: 1 ) if small-bodied species were more abundant under resource deficit at higher temperatures; 2) if there was a shift in dominance from small- to large-bodied species and vice versa based on the combined effects of temperature and food resources; and 3) how temperature influenced clearance rates in small- and large-bodied zooplankton.

\section{METHODS}

Three cladoceran species were used in this experiment: Daphnia magna Straus (adult body $=2.00 \pm 0.08 \mathrm{~mm}$, mean size + standard error), Daphnia pulex Leydig (1.6 $\pm 0.06 \mathrm{~mm}$ ) and Ceriodaphnia quadrangula O.F. Müller $(0.48 \pm 0.01 \mathrm{~mm})$. The first two species are considered large-bodied and the last is considered small-bodied. $D$. magna were obtained from laboratory cultures, D. pulex were collected from a pond near Lake Mikolajskie (Northern Poland), and C. reticulata were collected from Lake Mikolajskie. Prior to the start of the experiment, the cladocerans were cultured in $500 \mathrm{ml}$ beakers in a flow-through system. The cultures were supplied with lake water that was collected from Lake Mikolajskie at a depth of $2 \mathrm{~m}$, roughly $200 \mathrm{~m}$ from the shore line. The water in the beakers was exchanged daily.

To initiate the experiments, water was collected from Lake Mikolajskie and filtered through a 50 micrometer sieve to remove zooplankton. The experiments were conducted in $500 \mathrm{ml}$ beakers that were suspended in 100 $\mathrm{L}$ aquaria that were temperature regulated with coolers and heaters with relay. Two replicates of each of the three species in monocultures and three species grown together in polycultures were established by adding 5 - 6 mature individuals of each species from the laboratory cultures to the appropriate monocultures and polycultures beakers. Experiments were conducted at $15^{\circ} \mathrm{C}, 21^{\circ} \mathrm{C}$ and $27^{\circ} \mathrm{C}$. A long-day summer photoperiod (16:8 L:D) was applied. Green algae Scenedesmus quadricauda was added at a chlorophyll concentration of $14 \mu \mathrm{g} / \mathrm{L}$ to the flow-through system to increase food levels. Chlorophyll concentration was measured using a PhytoPam fluorometer (Walz, Germany). After the 10th day of the experiments the concentration of $S$. quadricauda was reduced 2-fold in the flow through system (e.g., $7 \mu \mathrm{g} / \mathrm{L}$ chlorophyll). This was done so that overcrowding did not occur in the beakers. This reduction of food concentration can be considered as a simulation of clear-water phase in lake ecosystems when changes in community structure can occur. The experiments were maintained for 45 days in July-August 2011. Every 5 days we counted the number of eggs and the number of juvenile and adult individuals 
of each species in each experimental beaker. During counting, animals were removed from the beakers, counted alive and then returned to the beakers. The biomass of each species was estimated for juveniles and adults using length weight regressions developed by [22] The total biomass was measured as the sum of juvenile and adult biomass for each species individually. Egg number is a good predictor of food conditions in Daphnia [23]. Hence we also determined fecundity (number of eggs per adult female, eggs/female) for each taxa in mono- and polycultures to asses food conditions.

Clearance rate was measured for $D$. pulex, D. magna and $C$. quadrangula at each of the three experimental temperatures. Because the cladoceran species used in this experiment varied in body-size, clearance rates were corrected for biomass and presented as $\mu \mathrm{g}$ Chl filtered/mg biomass of cladocera/hour. In these experiments we used Lake Mikolajskie water that was first filtered through the sieve to remove all the non-edible particles over $30 \mu \mathrm{m}$ [24-26]. To initiate the clearance rate experiments, 200 individual C. quadrangula, $100 \mathrm{D}$. magna, or $100 \mathrm{D}$. pulex were placed in $200 \mathrm{~mL}$ beakers with filtered lake water for 4 hours. An additional control treatment (no cladocerans) was also replicated in triplicate beakers to account for algae sedimentation. Chlorophyll $a$ was measured both before and after each experiment using a PhytoPam (Walz, Germany) fluorometer after each beaker was gently shaken. Clearance rate was determined as the difference in chlorophyll concentration in control beakers and in test beakers for each the three study species. Clearance rates were compared using two-way Analysis of Variance (ANOVA) where species and temperature were the two factors.

\section{RESULTS}

\subsection{Dynamics in Monocultures}

On day 10 of the experiment, the biomass of $D$. magna was highest at $27^{\circ} \mathrm{C}$ and lowest at $15^{\circ} \mathrm{C}$ (Figure 1(a)). After the food supply was reduced on day 10 , the biomass of D. magna continued to increase at each of the three temperatures mainly due to somatic growth. However, populations of $D$. magna began to decline first at the highest temperature with populations going extinct on day 29 at $27^{\circ} \mathrm{C}$, on day 37 at $21^{\circ} \mathrm{C}$ and on day 41 at $15^{\circ} \mathrm{C}$. During the period of higher food supply (e.g., days 1 - 10), the maximum fecundity for D. magna was 8,6 and 8 eggs/female at $15^{\circ} \mathrm{C}, 21^{\circ} \mathrm{C}$ and $27^{\circ} \mathrm{C}$, respectively. When the food supply was reduced after day 10 , fecundity gradually declined to zero by day 33 at $15^{\circ} \mathrm{C}$, day 21 at $21^{\circ} \mathrm{C}$ and day 13 at $27^{\circ} \mathrm{C}$ (Figure 1 (a)).

The monoculture population dynamics of the other large-bodied species $D$. pulex were similar to those observed for D. magna at each of the three temperatures

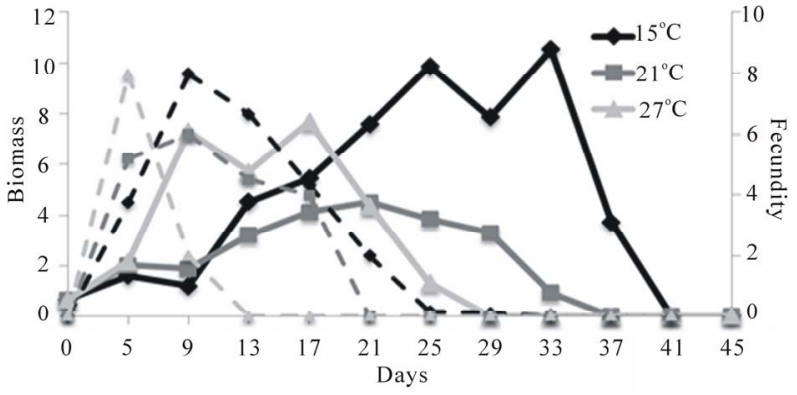

(a)

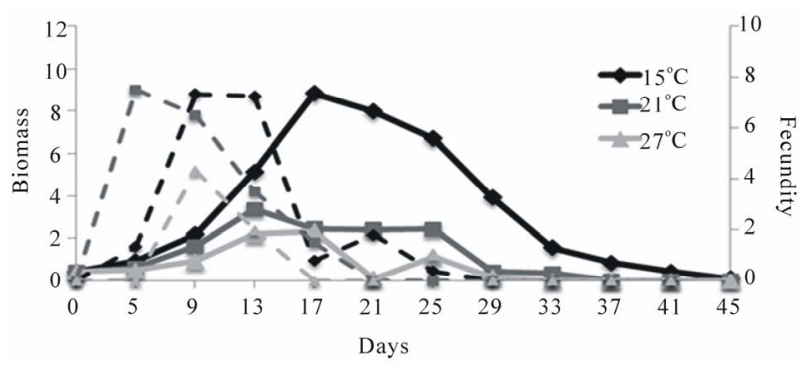

(b)

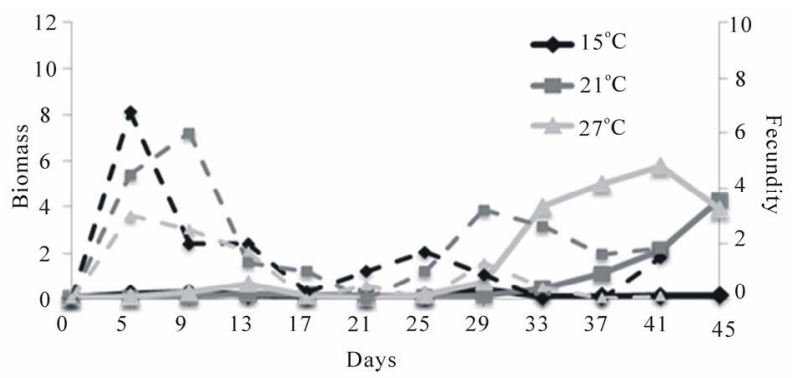

(c)

Figure 1. Mean biomass (mg per experimental bottle, $500 \mathrm{~mL}$; solid lines) and fecundity (eggs/adult female; dashed lines) of D. magna (a), D. pulex (b) and C. quadrangula (c) in monocultures at three different temperatures. Food supply was reduced two-fold on day 10 of the experiment.

(Figure 1(b)). The highest biomass on day 10 was observed at $15^{\circ} \mathrm{C}$ and the lowest biomass was observed at $27^{\circ} \mathrm{C}$. After day 10 there was a short period where biomass increased and the highest peak of biomass was observed at $15^{\circ} \mathrm{C}$ while the lowest peak of biomass was observed at $27^{\circ} \mathrm{C}$. As with $D$. magna, this large-bodied species went extinct earlier in the experiments at warmer temperature: $D$. pulex survived until day 45 at $15^{\circ} \mathrm{C}$, day 37 at $21^{\circ} \mathrm{C}$ and day 33 at $27^{\circ} \mathrm{C}$. Maximum fecundity prior to the reduction in food supply on day 10 was 7,7 and 4 eggs/female at $15^{\circ} \mathrm{C}, 21^{\circ} \mathrm{C}$ and $27^{\circ} \mathrm{C}$, respectively. When the food supply was reduced, fecundity gradually declined to zero by day 29 at $15^{\circ} \mathrm{C}$, day 21 at $21^{\circ} \mathrm{C}$ and day 17 at $27^{\circ} \mathrm{C}$.

The biomass of $C$. quadrangula was low during the first $\sim 25$ days of the experiment regardless of food supply and temperature (Figure 1(c)). Following this period 
of low growth, the biomass of $C$. quadrangula exhibited the sharpest increase and highest peak biomass at $27^{\circ} \mathrm{C}$. At $15^{\circ} \mathrm{C}$ the biomass of $C$. quadrangula did not increase and remained low until the end of the experiment. Fecundity was the highest with enhanced food supply during the first 10 days with 6,6 and 3 eggs/female at $15^{\circ} \mathrm{C}$, $21^{\circ} \mathrm{C}$ and $27^{\circ} \mathrm{C}$, respectively. After the reduction of food supply on day 10 , fecundity of $C$. quadrangula was low and rarely exceeded 2 eggs/female regardless of temperature. However, the biomass of $C$. quadrangula continued to increase at higher temperatures because the duration of juvenile development diminishes with rising temperature and birth rate increases [27].

\subsection{Dynamics in Polycultures}

At $15^{\circ} \mathrm{C}$ D. magna had the highest biomass of the three species through the first 10 days of enhanced food supply and until day 33 when its biomass decreased (Figure 2(a)). D. magna reached its peak biomass on the day 21, which was a little lower than in monoculture. The biomass of $C$. quadrangula was extremely low over the course of the experiment and was lower than in monoculture. The biomass of $D$. pulex was also lower in polyculture than it was in monoculture. After the biomass of D. magna declined on day 33, the biomass of C. quadrangula started to increase; however, it never exceeded 1 mg (Figure 2(a)).

The dynamics of the three species at $21^{\circ} \mathrm{C}$ were different to those observed at $15^{\circ} \mathrm{C}$. D. magna dominated during the first 10 days of the enhanced food supply, the biomass of $D$. pulex was less than the biomass of $D$. magna and the biomass of $C$. quadrangula was low at the start of the experiment (Figure 2(b)). On day 29 after the decline in biomass of the two large-bodied species the biomass of $C$. quadrangula began to increase. The difference in the dynamics of the three species between the $21^{\circ} \mathrm{C}$ and $15^{\circ} \mathrm{C}$ treatments was that biomass of $C$. quadrangula reached much higher levels at $21^{\circ} \mathrm{C}$ than at $15^{\circ} \mathrm{C}$.

At $27^{\circ} \mathrm{C}$ the biomass of $C$. quadrangula remained low until the extinction of the large-bodied species (Figure 2 (c)). D. magna dominated the first 10 days with enhanced food supply and continued to exhibit the highest biomass until day 25. However, the maximum biomass of D. magna in polyculture was less than its maximum biomass in monoculture. D. pulex also exhibited lower biomass in polyculture than in monoculture. D. magna and $D$. pulex went extinct in the polycultures at $27^{\circ} \mathrm{C}$ on day 29 and day 33, respectively. As the biomass of $D$. magna and D. pulex declined, C. quadrangula started to increase and it reached a peak biomass that was similar to that observed in monoculture.

Fecundity is considered as a good indicator of food conditions. Fecundity in the polycultures at each of the

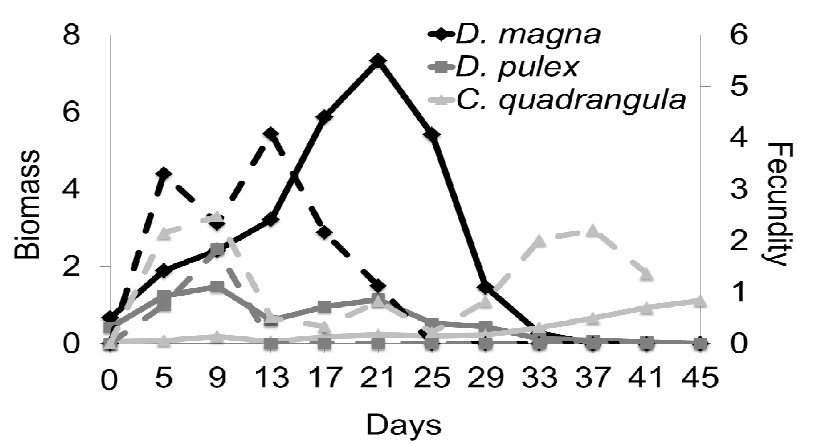

(a)

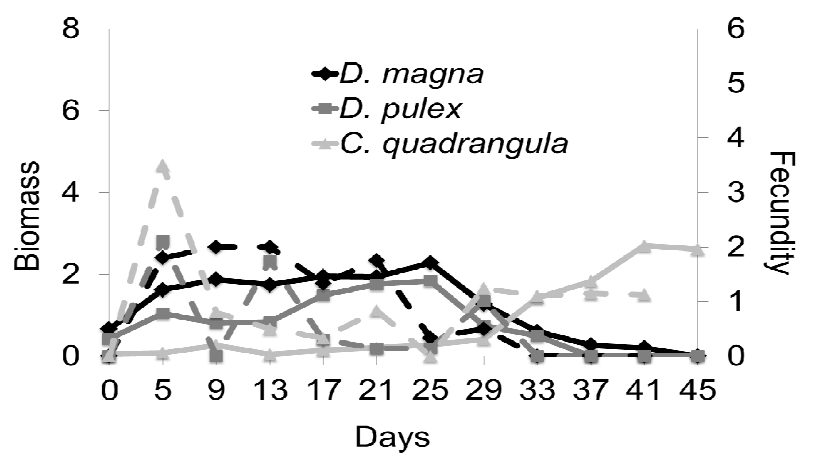

(b)

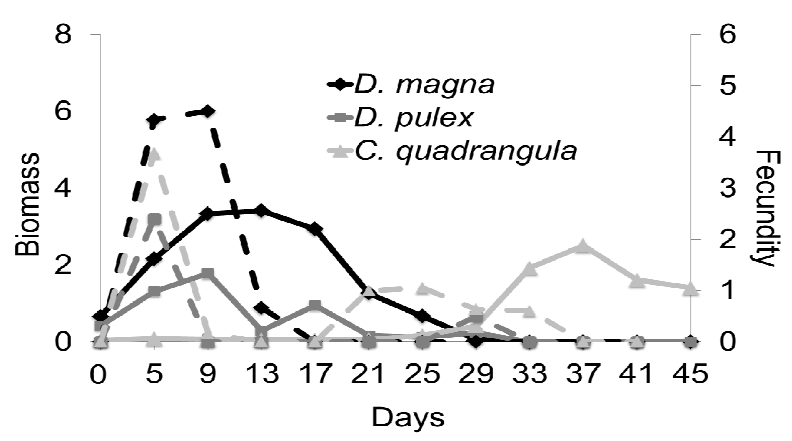

(c)

Figure 2. Mean biomass (mg per experimental bottle, $500 \mathrm{~mL}$; solid lines) and fecundity (eggs/adult female; dashed lines) of the three cladoceran species in polycultures at $15^{\circ} \mathrm{C}$ (a), $21^{\circ} \mathrm{C}$ (b) and $27^{\circ} \mathrm{C}$ (c). Food supply was reduced two-fold on the 10th day of the experiment.

three temperatures was less than in the respective monocultures for each of the three species (Figure 2). Fecundity was generally the highest during the first 10 days of the experiments, after which it declined more abruptly at $27^{\circ} \mathrm{C}$ than it did at the lower two temperatures. Fecundity of $C$. quadrangula resulted in a second peak after the biomass of the large-bodied species decreased. The increase in fecundity of $C$. quadrangula was higher at $27^{\circ} \mathrm{C}$ than it was at the other two temperatures.

Total biomass in each of the two replicates for all three species combined in polycuture was most stable at $21^{\circ} \mathrm{C}$. The dynamics of total biomass were different at the other 
two temperatures (Figure 3). The total biomass at $15^{\circ} \mathrm{C}$ decreased at the end of the experiment presumably because $C$. quadrangula could not compensate for losses in the biomass of the large-bodied species due to food reduction and low temperatures. In contrast, at $27^{\circ} \mathrm{C} \mathrm{C}$. quadrangula was able to compensate for losses in biomass of large-bodied species following an overall decrease in biomass during the middle of the experiment.

\subsection{Clearance Rate}

Clearance rate per unit of biomass was significantly higher for the small-bodied C. quadrangula than it was for the two large-bodied cladocerans (ANOVA, species effect, $\mathrm{F}(2,18)=51.28, \mathrm{P}<0.001$ ) (Figure 4). While clearance rate sharply increased at $27^{\circ} \mathrm{C}$ for $C$. quad rangula, it decreased or exhibited little difference for $D$. magna and $D$. pulex with changes in temperature. Maximum values of clearance rate were recorded for $D$. magna and D. pulex at $21^{\circ} \mathrm{C}$ and for C. quadrangula at $27^{\circ} \mathrm{C}$. Minimum values of clearance were recorded for $D$. pulex at $27^{\circ} \mathrm{C}$, for $D$. magna at $18^{\circ} \mathrm{C}$ and for C. quadrangula at $21^{\circ} \mathrm{C}$.

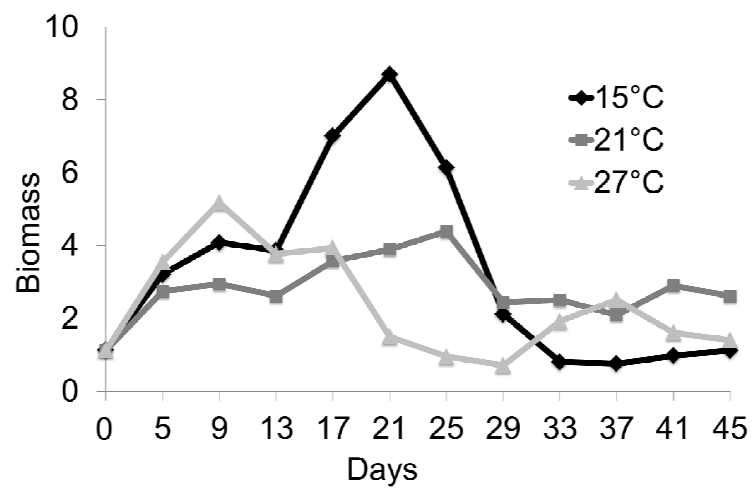

Figure 3. Mean biomass (mg per experimental bottle, 500 $\mathrm{mL}$ ) of the cladoceran species at $15^{\circ} \mathrm{C}, 21^{\circ} \mathrm{C}$ and $27^{\circ} \mathrm{C}$ in polycultures. Food supply was reduced two-fold on the 10th day of the experiment.

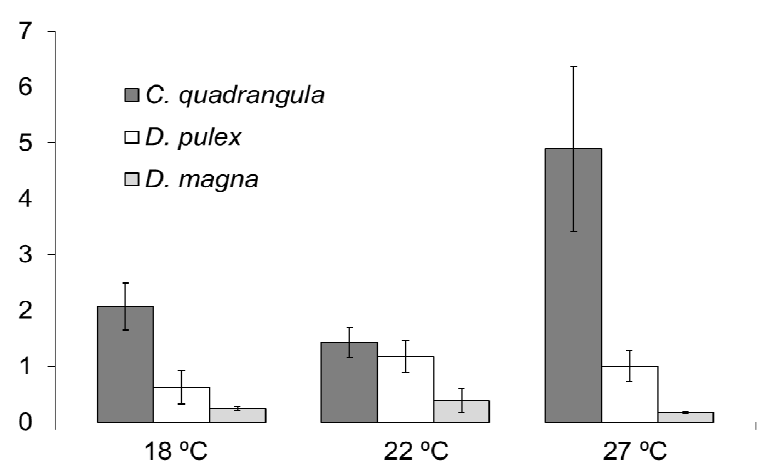

Figure 4. Clearance per for each of the three cladoceran species at the three experimental temperatures ( $\mu \mathrm{g} \mathrm{Chl} /$ hour/mg cladoceran biomass).

\section{DISCUSSION}

In contrast to previous predictions about cladoceran body size (e.g., SEH, [1,3]), our results support the hypothesis that there are shifts in dominance by large- and small-bodied cladocerans in response to coupled changes in temperature and food concentration. Specifically, high temperature combined with a high level of food supply resulted in conditions that favored D. magna and D. pulex; however, as the experiment progressed there was a reduction in food supply that favored $C$. quadrangula. While the biomass of the large-bodied $D$. magna began to decrease in response to the thermal and resource conditions, these conditions appeared to become more favorable for C. quadrangula which started to increase in biomass. We suggest that these changes in community composition were not driven by competitive exclusion, but instead by each species physiological and metabolic responses to the changes in environmental conditions.

Although there were major shifts in the biomass of the three taxa in polyculture at each temperature, there was little change in the total biomass of cladocerans over the course of the experiments. C. quadrangula was able to compensate for losses in the biomass of the large-bodied species at the two elevated temperatures. At the lowest temperature, however, the growth of $C$. quadrangula was too low to maintain the total biomass after the decline of the large-bodied species. The total biomass in our treatments was more stable at intermediate temperature than at either lower or higher temperatures. The relationship between species diversity and ecosystem stability is a central issue in ecological research [28]. Ecological theory suggests that increasing species richness of competitors can enhance the temporal stability of total competitor biomass $[29,30]$. With respect to zooplankton, Steiner [28] showed that temporal variation in zooplankton biomass decreased with increasing taxonomic richness. While the mechanisms associated with this phenomenon are not well understood, our results provide a possible mechanism that helps to maintain a stable level of competitor biomass through species replacement along environmental gradients. Such mechanism of species replacement in the polycultures over time resembles the conceptual model of substitutive facilitation which occurs when a novel species functionally replaces a native species [31]. While food and thermal conditions for the large-bodied species deteriorated, they become more appropriate for $C$. quadrangula which started to grow and compensate for biomass losses by large-bodied species. Similar replacement was described by Lennon et al. [10]. Synergistic interactions between low quality food and elevated water temperatures explained late summer declines for some Daphnia populations in Clinton Reservoir (Kansas, USA), while the small non-native $D$. lumholtzi successfully filled this gap in the total biomass 
of cladoceran species at temperatures between 26 and $31^{\circ} \mathrm{C}$.

In terms of fitness, we suggest that small- and largebodied species can be complementary. As our data suggest, population advantages can shift from large-bodied species to small-bodied species and vice versa as environmental conditions such as temperature and food concentration change. It has been suggested that population fitness can be estimated in terms of population growth rate, $r[5,19,32]$. However, the effects of food availability on $r$ may be dependent on the effects of temperature [33]. Daphniids cannot benefit from an increase in temperature if food is limiting. In fact, [19] and [5] found that the effects of temperature on $r$ were reduced under low resource conditions. Hence temperature and food concentration effects are clearly interrelated. Population rate of increase and somatic growth rate in $D$. magna are closely related to the juvenile growth rate $\left(g_{j}\right)$ [33]. The correlation is so strong that $g_{j}$ was suggested as a measure of fitness instead of $r$ to construct reaction norms [16]. Therefore maximum $g_{j}$ can be used as an estimate of population fitness and the higher $g_{j}$ is, the more abundant a population should be. If so, the combined effects of temperature and food supply on fitness can be depicted as in Figure 5. For large-bodied Daphnia, fitness is high at lower temperatures and higher food supply. For small-bodied Ceriodaphnia, however, fitness is high at higher temperatures and lower food supply due to enhanced foraging activity at higher temperature. In support, there are a number of studies showing that both low and high concentrations of algae can have negative effects on cladocerans and there are bell-shaped relationships between cladoceran demographic parameters and food concentration [20,34,35].

As the fitness of a population is associated with somatic growth [16,33], population fitness therefore can be understood through the relationship between clearance rate and temperature and how this relationship influences the physiological responses of cladocerans. As C. quadrangula enhanced its clearance rate at elevated tempera-

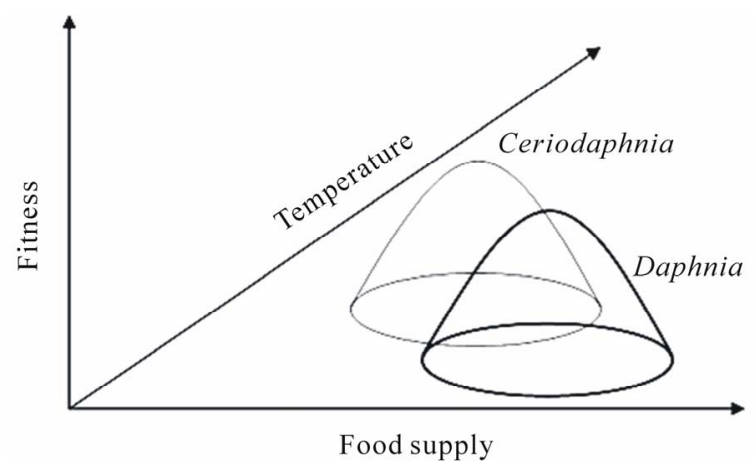

Figure 5. Proposed relationships between fitness, food supply and temperature for large-bodied Daphnia (black line) and small-bodied Ceriodaphnia (grey line) species. ture, the optimum level of clearance rate will shift along the food supply gradient to lower values as compared to large-bodied Daphnia sp. Gophen [36] also found that ingestion rate of Ceriodaphnia reticulata increased with increasing temperature from $15^{\circ} \mathrm{C}$ to $27^{\circ} \mathrm{C}$. Clearance rate of large-bodied species on the contrary decreases at higher temperatures. Corresponding with these changes in clearance rate, species advantages should change along environmental gradients. Hence mechanisms of the species replacement may be provided by physiological processes.

In support of our predictions (Figure 5), seasonal succession of zooplankton in temperate lakes has shown that large Daphnia species are replaced by small cladocerans in midsummer when water temperature increases and food supply declines [13,37]. Long-term warming was shown to shift zooplankton communities from largebodied to small-bodied taxa [38]. Biogeographical studies also suggest that small-bodied cladocerans are often dominant over large-bodied cladocerans in warm tropical and subtropical environments [13-15,39]; however, there are some exceptions. For example, large bodied Daphnia were found in India, Australia, New Zealand and African lakes [13,40-42,] and the large-bodied Daphnia magna was introduced into the warm Lake Victoria of the East African Great Lakes [43]. Such contradiction can be explained if temperature effects are considered in combination with food abundance. Our proposed mechanism of species replacement may help to explain why some small-bodied species invade oligotrophic but not eutrophic lakes [44]. The success of small-bodied species over large-bodied species at low food supply was also demonstrated by Goulden et al. [45] and Romanovski and Feniova [6]. When in the experiments food supply was enhanced, quantitative advantage shift to large bodied counterparts. Foran [5] also found that the small-bodied Daphnia laevis had a competitive advantage over the large-bodied Daphnia magna at elevated temperature and low food level.

To conclude, the advantage of cladoceran species can change in response to the coupled influences of temperature and food concentration. Small- and large-bodied species have different reactions to these environmental variables: small-bodied species dominate at lower food supply and higher temperature, while large-bodied species in contrast dominate at lower temperature and higher food supply. This mechanism of species replacement along environmental gradients helps to sustain the total biomass of cladoceran communities throughout a season. Such mechanisms are similar to facilitative replacement rather than competitive exclusion. Physiological processes such as clearance rate coupled with assimilation and respiration rates may help to facilitate the succession of populations in a community along gradients of tem- 
perature and food availability.

\section{ACKNOWLEDGEMENTS}

We are grateful to J. Uchmanski, J. Ejsmont-Karabin and I. Sawitska for constant assistance and providing opportunity to perform our studies at the Hydrobiological Station (Center for Ecological Research, Polish Academy of Sciences) in Mikolajki. This work was supported by the Polish Ministry of Sciences and Higher Education, the Russian-Belorussian Foundation for Basic Research and the Fulbright Program.

\section{REFERENCES}

[1] Brooks, J.L. and Dodson, S.I. (1965) Predation, body size and composition of plankton. Science, 150, 28-35. doi:10.1126/science.150.3692.28

[2] Achenbach, L. and Lampert, W. (1997) Effects of elevated temperatures on threshold food concentrations and possible competitive abilities of differently sized cladoceran species. Oikos, 79, 469-476. doi:10.2307/3546889

[3] Gliwicz, Z.M. (2003) Between hazards of starvation and risk of predation: The ecology of offshore animals. International Ecology Institute, Oldendorf/Luhe.

[4] Hanski, I. and Ranta, E. (1983) Coexistence in a patchy environment: Three species of Daphnia in rock pools. Journal of Animal Ecology, 52, 263-279. doi:10.2307/4599

[5] Foran, A.F. (1986) A comparison of the life history features of a temperate and a subtropical Daphnia species. Oikos, 46, 185-193. doi:10.2307/3565466

[6] Romanovsky, Y.E. and Feniova, I.Yu. (1985) Competitiona among cladocera: Effect of differentl evels of food supply. Oikos, 44, 243-252. doi:10.2307/3544696

[7] Dzialowski, A.R. and O’Brian, W.J. (2004) Is competition important to arctic zooplankton community structure? Freshwater Biology, 49, 1103-1111. doi:10.1111/j.1365-2427.2004.01250.x

[8] Hu, S. and Tessier, A.J. (1995) Seasonal succession and the strength of intra- and interspecific competition in a Daphnia assemblage. Ecology, 76, 2279-2294. doi:10.2307/1941702

[9] Caceras, C.E. (1998) Seasonal dynamics and interspecific competition in Oneida Lake Daphnia. Oecologia, 115, 233-244. doi:10.1007/s004420050512

[10] Lennon, J.T., Smith, V.H. and Williams, K. (2001) Influence of temperature on exotic Daphnia lumholtzi and implications for invasion success. Journal of Plankton Research, 23, 425-434. doi:10.1093/plankt/23.4.425

[11] Gyllström, M., Hansson, L.A., Jeppesen, E., García-Criado, F., Gross, E., Irvine, K., Kairesalo, T., Kornijow, R., Miracle, M.R., Nykänen, M., Nõges, T., Romo, S., Stephen, D., Van Donk, E. and Moss, B. (2005) The role of climate in shaping zooplankton communities of shallow lakes. Limnology and Oceanography, 50, 2008-2021.

[12] Thompson, P.L., St-Jacques, M.-C. and Vinebrooke, R.D. (2008) Impacts of climate warming and nitrogen deposi- tion on alpine plankton in lake and pond habitats: An in vitro experiment. Arctic, Antarctic, and Alpine Research, 40, $192-198$. doi:10.1657/1523-0430(06-105)[THOMPSON]2.0.CO;2

[13] Moore, M.V., Folt, C.L. and Stemberger, R.S. (1996) Consequences of elevated temperatures for zooplankton assemblages in temperate lakes. Archiv für Hydrobiologie, 135, 289-319.

[14] Sarma, S.S.S., Nandini, S. and Gulati, R.D. (2005) Life history strategies of cladocerans: Comparisons of tropical and temperate taxa. Hydrobiologia, 542, 315-333. doi:10.1007/s10750-004-3247-2

[15] Pinto-Coelho, R., Pinel-Alloul, B., Methot, G. and Havens, K.E. (2005) Crustacean zooplankton in lakes and reservoirs of temperate and tropical regions: Variation with trophic status. Canadian Journal of Fisheries and Aquatic Sciences, 62, 348-361. doi:10.1139/f04-178

[16] Giebelhausen, B. and Lampert, W. (2001) Temperature reaction norms of Daphnia magna: The effect of food concentration. Freshwater Biology, 46, 281-289. doi:10.1046/j.1365-2427.2001.00630.x

[17] Savage, V.M., Gillooly, J.F., Brown, J.H., West, G.B. and Charnov, E.L. (2004) Effects of body size and temperature on population growth. American Naturalist, 63, 429441. doi:10.1086/381872

[18] Tessier, A.J., Leibold, M.A. and Tsao, J. (2000) A fundamental trade-off in resource exploitation by Daphnia and consequences to plankton communities. Ecology, 81, 826841. doi:10.1890/0012-9658(2000)081[0826:AFTOIR]2.0.CO ;2

[19] Orcutt, J.D. and Porter, K.G. (1984) The synergistic effects of temperature and food concentration on life history parameters of Daphnia. Oecologia, 63, 300-306. doi:10.1007/BF00390657

[20] Gama-Flores, J.L., Huidobro-Salas, M.E., Sarma, S.S.S. and Nandini, S. (2011) Somatic and population growth responses of Ceriodaphnia dubia and Daphnia pulex (Cladocera) to changes in food (Chlorella vulgaris) level and temperature. Journal of Environmental Biology, 32, 489-495.

[21] Wetzel, R.G. (2001) Limnology: Lake and river ecosystems. 3rd Edition, Academic press, London.

[22] Balushkina, E.B. and Vinberg, G.G. (1979) Experimental and field studies of the productivity in the lakes. Nauka, Leningrad.

[23] Lampert, W. (1978) A field study on the dependence of the fecundity of Daphnia on food concentration. Oecologia, 36, 363-369. doi:10.1007/BF00348062

[24] Lampert, W. (1987) Laboratory studies on zooplankton-cyanobacteria interactions. New Zealand Journal of Marine and Freshwater Research, 21, 483-490. doi:10.1080/00288330.1987.9516244

[25] Bloem, J. and Vijverberg, J. (1984) Some observations on the diet and food selection of Daphnia hyalina (Cladocera) in an eutrophic lake. Hydrobiological Bulletin, 18, 39-45. doi:10.1007/BF02256672

[26] Dawidowicz, P. (1990) The effect of Daphnia on filament 
length of blue-green algae. Hydrobiologia, 191, 265-268. doi:10.1007/BF00026061

[27] Feniova, I.Yu. and Zilitinkevich, N.S. (2012) Dependence of demographic parameters and results of competition on temperature in cladocerans. Russian Journal of Ecology, 43, 131-136. doi:10.1134/S1067413612010055

[28] Steiner, C.F. (2005) Temporal stability of pond zooplankton assemblages. Freshwater Biology, 50, 105-112. doi:10.1111/j.1365-2427.2004.01310.x

[29] Doak, D.F., Bigger, D., Harding, E.K., Marvier, M.A., O’Malley, R.E. and Thomson, D. (1998) The statistical inevitability of stability-diversity relationships in community ecology. American Naturalist, 151, 264-276. doi:10.1086/286117

[30] Tilman, D., Lehman, C. and Bristow, C.E. (1998) Diversity stability relationships: Statistical inevitability or ecological consequence? American Naturalist, 151, 277-282. doi:10.1086/286118

[31] Rodriguez, L.F. (2006) Can invasive species facilitate native species? Evidence of how, when, and why these impacts occur. Biological Invasions, 8, 927-939. doi:10.1007/s10530-005-5103-3

[32] Sakwinska, O. (1998) Plasticity of Daphnia magna life history traits in response to temperature and information about a predator. Freshwater Biology, 39, 681-687. doi:10.1046/j.1365-2427.1998.00320.x

[33] Lampert, W. and Trubetskova, I. (1996) Juvenile growth rate as a measure of fitness in Daphnia. Functional Ecology, 10, 631-635. doi:10.2307/2390173

[34] Lynch, M. and Ennis, R. (1983) Resource availability, maternal effects, and longevity. Experimental Gerontology, 18, 147-165. doi:10.1016/0531-5565(83)90008-6

[35] Dodson, S.I. and Frey, D.G. (2001) Cladocera and other branchiopoda In: Thorp, J.H. and Covich, A.P., Eds., Ecology and Classification of North American Freshwater Invertebrates, Academic Press, London, 850-914. doi:10.1016/B978-012690647-9/50022-3

[36] Gophen, M. (1976) Temperature dependence of food intake, ammonia excretion and respiration in Ceriodaphnia reticulata (Jurine) (Lake Kinneret, Israel). Freshwater Biology, 6, 451-455. doi:10.1111/j.1365-2427.1976.tb01634.x
[37] DeMott, W.R. (1989) The role of competition in zooplankton succession. In: Sommer, U., Ed., Plankton Ecology, Springer-Verlag, Berlin, 195-252. doi:10.1007/978-3-642-74890-5_6

[38] Holzapfel, A.M. and Vinebrooke, R.D. (2005) Environmental warming increases invasion potential of alpine lake communities by imported species. Global Change Biology, 11, 2009-2015. doi:10.1111/j.1365-2486.2005.001057.x

[39] Atkinson, D. (1994) Temperature and organism size a biological law for ectotherms? Advances in Ecological Research, 25, 1-58. doi:10.1016/S0065-2504(08)60212-3

[40] Green, J. (1967) The distribution and variation of Daphnia lumholtzi (Crustacea: Cladocera) in relation to fish predation in Lake Albert, East Africa. Journal of Zoology (London), 151, 181-197. doi:10.1111/j.1469-7998.1967.tb02872.x

[41] Chapman, M.A. and Lewis, M.H. (1976) An introduction to the freshwater Crustacea of New Zealand. HarperCollins Publishers Ltd, Auckland.

[42] Venkataraman, K. (1981) Field and laboratory studies on Daphnia carinata King (Cladocera: Daphnidae) from a seasonal tropical pond. Hydrobiologia, 78, 221-225. doi:10.1007/BF00008518

[43] Jonna, R. and Lehman, J.T. (2004) Invasion of Lake Victoria by the large bodied herbivorous cladoceran Daphnia magna. In: Odada, E.O. and Olago, D.O., Eds., The East African Great Lakes: Limnology, Palaeolimnology and Biodiversity. Springer, Netherlands, 321-333. doi:10.1007/0-306-48201-0_12

[44] Dzialowski, A.R., O’Brian, W.J. and Swaffarl, S.M. (2000) Range expansion and potentially dispersal mecha- nisms of the exotic cladoceran Daphnia lumholtzi. Jour- nal of Plankton Research, 22, 2205-2223. doi:10.1093/plankt/22.12.2205

[45] Goulden, C. E., Henry, L.L. and Tessier, A.J. (1982) Body size, energy reserves and competitive ability in three species of Cladocera. Ecology, 63, 1780-1789. doi:10.2307/1940120 